\title{
Ciencia y Ficción en los Cuentos de Leopoldo Lugones
}

\author{
Os cuentos cientificistas de Leopoldo Lugones constituyen una parte \\ 1 relativamente pequeña pero importantísima, la menos estudiadal \\ por cierto y seguramente la menos leída, de su variada y compleja obra \\ literaria. Son $\operatorname{doce}^{2}$ los relatos que componen Las fuerzas extrañas, ${ }^{3}$ pri- \\ mer libro de ficciones del autor argentino que con él inicia su distinguida
}

1 Es sumamente escasa la bibliografía crítica sobre esta obra; el mejor trabajo que he leído es Emma Susana Speratti Piñero, "La expresión de las "fuerzas extrañas' en Leopoldo Lugones" en La literatura fantástica en Argentina (México: Imprenta Universitatia, 1957), pp. 1-16 (es coautora Ana María Barrenechea a quien pertenecen varios capítulos). No he podido consultar la obra de Nicolás Cócaro, Cuentos fantásticos argentinos (Buenos Aires: Emecé Editores, 1960). Cito frecuentemente las opiniones de Jorge Luis Borges dispersas en Leopoldo Lugoner (Buenos Aires: Editorial Troquel, 1955) y acertados aunque escasos juicios de otros críticos (Guillermo Ara, Juan Carlos Ghiano, Antonio Pagés Larraya) que se han ocupado en menos detalle que los anteriores de esta obra. Por lo demás, una que otra escueta, a veces desdeñosa, alusión a refundiciones de material bíblico o legendario y a historias de magia y ciencias ocultas en diversos estudios dedicados a otras facetas del arte lugoniano dejan una impresión totalmente errónea de estos relatos.

2 La clasificación de las doce narraciones del libro (cinco cientificistas: "La fuerza omega", "La metamúsica", "Yzur", "Viola acherontia", "El psychón"; dos que oscilan entre la ciencia y la filosofía: "Un fenómeno inexplicable" y "El origen del diluvio"; y cinco legendarias, entendiéndose por ello las narraciones basadas en asuntos bíblicos, leyendas folklóricas, milagros cristianos y mitos griegos: "La lluvia de fuego", "El milagro de San Wilfrido", "El escuerzo", "Los caballos de Abdera" y "La estatua de sal") que propone Emma Susana Speratti Piñero ("La expresión de las 'fuerzas extrañas' en Leopoldo Lugones", pp. 1.2 y ss.) me parece muy lógica y útil.

3 Hay tres ediciones de la obra: (Buenos Aires: Arnaldo Moen y Hno., editores, 1906; Buenos Aires: M. Gleizer, editor, 1926; Buenos Aires: Editorial Centurión [Colección Ulises, 12], 1948). Para este estudio he utilizado la edición de 1926 y a ella corresponden todas las citas textuales. "La lluvia de fuego" puede leerse en Leopoldo Lugones, Antología de la prosa (Buenos Aires: Editorial Centurión [Colección Ulises, 15], 1949, [Selección y comentario inicial de Leopoldo Lugones (hijo)], pp. 86-96). "Yzur" ha sido incluido en Veinte Cuentos Hispanoamericanos del Siglo XX (New York: Appleton-Century-Crofts, Inc., 1956, [Edited with Introduction, Notes, and Vocabulaty by Entique AndersonImbert and Lawrence B. Kiddle], pp. 17-26). La interesante colección 20 fic- 
Jabor en el campo de la ficción científica." El volumen contiene además lo que el autor llama "ensayo de una cosmogonía en diez lecciones" que a su vez va precedido de un proemio (págs. 1.73 -175) y seguido de un epílogo (págs. 23I-233).

Este modo de encuadrar el libro, exposición más o menos sistemática de una teoría, trasladada luego al nivel ficcional en forma de relatos ilustrativos, recuerda el procedimiento de Edgar Allan Poes que en The Murders in the Rue Morgue introduce una larga disquisición sobre el análisis deductivo, distinguiéndolo de la simple ingeniosidad, para entrar

ciones argentinas 1900-1930 (Buenos Aires: Editorial Universitatia, 1963 [Selección y prólogo de Antonio Pagés Larraya]), contiene agudas observaciones generales sobre Las fuerzas extrañas (p. 8) y un bosquejo cronológico-bibliográfico (pp. 140-142), pero el texto del rélato de Lugones elegido por Pagés Larraya para la antología ("El escuerzo") no aparece.

4 Es necesario precisar y limitar, en dos sentidos esenciales, relacionados, en realidad, a la relativa importancia que les es concedida en la obra literaria a sus dos elementos constitutivos, ficción y ciencia, la aplicación de este término a Las fuerzas extrañas. La complejidad técnica y temática de esta obra requiere, por ejemplo, que al llamarla ficción científica, se agregue que difiere, por un lado, debido a la presencia de ciertos recursos literarios (la ironía, la sátira, el humor burlesco) de la mayor parte de las obras que comúnmente lhevan tal denominación y por el otro, que estos cuentos se distinguen, en virtud de la rigurosa base cien. tífica que los respalda, de aquel grupo de obras menos valiosas desde el punto de vista literario, aunque no por ello menos difundidas, de pura y exagerada fantasía en que poco o nada importa la relación que puedan tener con la ciencia. El tono satírico-burlesco de que varios cuentos de Las fuerzas extrañas están impregnados se debe en parte al hecho de que a pesar de su profundo interés y fe en la ciencia, Lugones no tenia ilusiones ingenuas respecto de su total infalibilidad, es decir de su aplicación universal. Además, a muy pocos lectores de Lugones les ha de sorprender la presencia de cierta tendencia escéptica de elástica intensidad que va de humor ligeramente burlesco ("La fuerza omega", "El psychón") a un marcado sentimentalismo ("Yzur"), en vista del concepto de Lugones cuentista, lugar común ya de la crítica, que lo toma por romántico, en la tradición de Edgar Allan Poe, tendencia que sin duda informa gran parte de lo que podríamos llamar elaboración paracientífica en el escritor argentino. Estos dos reparos indispensables a la interpretación de Lugones como escritor de ficción científica permiten mayor ahondamiento en la esencia de los relatos y ayudan a explicar su valor literario. Es consecuencia lógica de este doble factor (ficción basada en una concepción rigurosamente científica y matiz satírico-burlesco producto de una predisposición espiritual del autor hacia el escepticismo) que los relatos de hecho comparten valores literarios de dos tipos de narración, a saber, el misterio, el suspenso y la sorpresa de la mejor ficción científica y la fuerza dramática del relato que por conveniencia llamaremos realista. Además, eluden los defectos tradicionales de que éstos a veces adolecen, y que son, respectivamente, exceder el grado a que es razonable suponer que el lector estaría dispuesto a aceptar vuelos de fantasía a regiones más o menos disparatadas, $v$ el pesado moralismo y didacticismo que puede anular el efecto de la narración (excepto, claro está, en manos de los maestros supremos de los géneros aludidos). A mi juicio este volumen de cuentos se salva holgadamente de estos posibles defectos.

5 John E. Englekirk (Edgdr Allan Poe in Hispanic Literature, Nueva York, 1934, pp. 278-304) examina otros varios aspectos de la influencia de Poe en Lugones; a propósito de Las fuerzas extrañas, su conclusión general es que dicha influencia es palpable pero difícil de concretar (p. 293). 
después en la narración que en palabras del autor "will appear to the reader somewhat in the light of a commentary upon the propositions just advanced". 6 Aunque seria tan inexacto sostener que la eficacia de los cuentos lugonianos depende del ensayo como lo sería afirmar que las aventuras de Auguste Dupin perderian su interés de no tener el lector a la vista un resumen sistemático del proceso de "ratiocination", se ven con toda claridad los aspectos más significativos de la función del "ensayo de una cosmogonía" que, como veremos, responde no tanto al arte del cuentista como a las necesidades del apologista de la ciencia. No deja de tener cierto interés el paralelo, sobre todo en vista de que más adelante en el relato de Poe los protagonistas discuten asuntos "cosmogónicos",7 si bien es cierto, al mismo tiempo, que en éste como en otros muchos pormenores son tan patentes las diferencias como las semejanzas entre los dos cuentistas.

El libro tiene, en realidad, tres partes: la de los cuentos, la que consiste en las diez lecciones del ensayo y finalmente el proemio y el epílogo del ensayo que por una razón muy sencilla - aquí, a diferencia del resto del libro, no hay ni un gramo de ficción o fantasía intencionales, y Lugones nos está hablando muy en serio-forman una tercera sección que se distingue nítidamente del resto de la obra y que contiene implícita la concepción de las "fuerzas extrañas", es decir, la visión de su efectividad y alcance, y el sentido del pensamiento del poeta-filósofo en esta esfera.

En el proemio aparece un casual y misterioso interlocutor, de tipo y edad indefinibles - se insiste en esto, como en su desaparición posterior, con la cual se justifica la intromisión de un lego en asuntos científicos-cuya elocuencia fascina de tal manera al autor que éste se halla dispuesto a aceptar sin objeción alguna "ideas... de las más extraordinarias". 8 Más adelante, Lugones nos explica que a propósito de la revelación:

Por mucho que difiera de las ideas cientificas dominantes, el lector apreciará su concepción profunda, su lógica perfecta, y comprenderá que explica bastantes cosas con mayor claridad aún. ${ }^{9}$

No es difícil adivinar que se trata de distintos aspectos del espíritu inquieto y curioso del autor, uno en que predominan la tendencia científica

6 The Centenary Poe (London: Hazell, Watson \& Viney, Ltd., 1949, [edited and with an introduction by Montagu Slater], p. 249).

7 Ibid, pp. 251-252.

8 Las fuerzas extrañas, p. 173.

9. Ibid, p. 174 . 
y el deseo de exponer sucinta y seriamente los postulados de la ciencia de su tiempo, y otro en que se manifiesta la intuición poética, el presentimiento de las "fuerzas extrañas" ligado al afán de indagar y explicar lo inexplicable que son el punto de partida de la elaboración imaginativa del ensayo y de la subsiguiente ficción de los cuentos. ${ }^{20}$ Como dice Jorge Luis Borges, ${ }^{11}$ el propósito del autor es expresar seriamente una hipótesis, pero sucede que gran parte de la cosmogonía lugoniana evidentemente no es susceptiva a la verificación dentro del sistema científico de su dia, sino que representa una serie de proyecciones intuitivas, más o menos reconciliables con dicho sistema, a regiones no comprendidas por él. El mérito de Lugones como escritor de ficción científica se ha de medir teniendo presente, como elemento primordial, esta relación ciencia-ficción, y figurarán ciertamente entre las dimensiones más notables de su arte narrativo la asombrosa riqueza de invención en este sentido, y tal vez más importante desde el punto de vista estético, la destreza con que el autor ha conseguido mantener en perfecto equilibrio artístico los resortes temáticos de sus relatos, sin desvirtuar ni el elemento científico ni el ficticio.

Se debe precisamente a su constante respeto por los postulados de las ciencias exactas, de los cuales inventa variantes y sobre los cuales improvisa ingeniosamente, pero sin desentenderse de ellos ni por un instante, que Lugones se incorpora a la larga y fecunda tradición de la ficción científica literaria, tradición que difiere radicalmente en profundidad y valor artístico de la otra, a veces antiliteraria, en que los autores, por falta de conocimientos científicos o desinterés, entre otras causas, permiten que sus narraciones degeneren en sensacionalismo pueril.12

10 Se sobrentiende que la materia del ensayo es conceptualmente anterior a los cuentos y no deja de serlo por estar impresa al final del libro.

11 Leopoldo Lugones, p. 72.

12 En un repaso de la larga y compleja historia de la ficción científica, Patrick Moore (Science and Fiction, London, 1957) propone un par de categorías sumamente útiles para el estudio de este tipo de literatura ("Introduction", p. 10). La primera consiste en aquellas obras cuyo autor ha tenido en cuenta constantemente y sin alejarse de ellos o tergiversarlos demasiado, los postulados científicos de su época, a fin de que éstos sirvan, sea en el cuento o en la novela, de resorte principal a la narración. Como señala Moore, esto no supone limitación alguna, a menos que escaceen la fuerza imaginativa del autor o sus conocimientos científicos; al contrario, la base científica, aparte de su valor instructivo, es punto de referencia para las elaboraciones e improvisaciones ficticias del relato que de ahi cobran mayor trascendencia y que hacen patente, por lo tanto, la diferencia entre la fantasía sugestiva y el desliz absurdo. La segunda de las categorías de Moore se refiere a obras en que la ciencia es ignorada por completo o--y esto es lo más funesto en sus consecuencias-a aquellas narraciones que por inversión caprichosa o incompetente resultan no sólo inconcebibles, es decir de una inverosimilitud infantil, sino literalmente anticientíficas. Sobra decir que sólo en la primera de estas categorías se han de busca: valores literatios. La segunda le ha valido a gran 
La obra fue publicada por primera vez en $1906,{ }^{13}$ a un año de la aparición de La guerra gaucha, pero estos dos hechos no son del todo casuales; al contrario, obedecen a ciertas cualidades fundamentales del escritor, y se prestan por ello al esclarecimiento de una importante faceta de su variado talento.

La guerra gaucha es una obra de índole épica, en que los hechos históricos, o sea, reales, son aprovechados como materia prima y tratados imaginativamente - de la misma forma que ocurren los mitos en la imaginación popular - en tanto que la novela, El ángel de la sombra (1926), es obra de pura imaginación. En la primera Lugones tuvo éxito, al menos en el plano estilístico. En la actual reestimación de Lugones se reconoce cada vez más el valor de su obra literaria y aunque el libro sobre la guerra del norte ocupa ahora un lugar de preferencia entre las obras nacionales, es evidente que al principio el eco popular fue mínimo ante La guerra gaucba. No obstante, la obra merece considerarse uno de los grandes aciertos de la prosa modernista en la Argentina, como lo fue por los mismos años La gloria de don Ramiro, de Entique Larreta. El ángel de la sombra, en cambio, no fue recibida con aplauso en su tiempo, ni lo es ahora; se reconocen en ella ciertamente las excelencias estilísticas, factor común a casi todas las obras de Lugones; se admira la presentación como tema central de un fatalismo de ascendencia oriental - tratado ya en la colección Cuentos fatales (I 924) - pero le faltan las cualidades esenciales de la novela como género: caracteres bien dibujados, interés argumental, diálogo eficaz y tensión sostenida.

Teniendo en cuenta estos detalles de su obra en prosa se puede inferir que Lugones fue un excelente cuentista y un brillante ensayista, pero que en realidad no estaba dotado para la novela. Además, su intelecto

parte de la ficción científica una posición de muy poco prestigio, cuando na la de una perversión literaria - debido indudablemente a la proliferación torrencial de folletines pueriles en la década del treinta-en el panorama literario del siglo veinte. Es lamentable que los cuentos de Lugones le fueran totalmente desconocidos al escritor inglés, porque de haberlos leído habría podido agregar, sin vacilar, interesantes páginas a los capítulos que dedica a la primera de sus categorías. Habría verificado, por ejemplo, que algunos de los relatos de Las fuerzas extrañas, los seis cientificistas, representan un intento ejemplar y logrado en cuanto a valor literario, de elaboración imaginativa sobre un fondo de conceptos científicos tan riguroso como lo permitían los conocimientos de su tiempo.

13 No se sabrá con precisión la verdadera fecha de composición de todos los relatos hasta que se aclaren estas palabras que se hallan en la "advertencia" a la edición de 1926 y que dan a entender, pero sin detalles, que algunos cuentos de la colección son anteriores aun a 1906: "Algunas ocurrencias de este libro, editado veinte años ha, aunque varios de sus capítulos corresponden a una época más atrasada todavía, son corrientes ahora en el campo de la ciencia". 
tenía una marcada orientación científica, ${ }^{14}$ como lo prueban la insaciable curiosidad, el afán experimental y la claridad expositiva. Un espíritu así dispuesto a la experimentación y a la especulación científica, unido al don poético, ha dado un resultado muy feliz ${ }^{15}$ en la creación de literatura cientificista. Por otra parte, la publicación de Las fuerzas extrañas evidentemente corresponde a un intervalo de fluidez, desenvoltura y regocijo en la ejecución de una tarea grata, entre el bullicio de la polémica, de los cargos oficiales y de las cruzadas lingüístico-literarias. ${ }^{16}$ Basta una ojeada a las actividades intelectuales de Lugones durante los años inmediatos a la com* posición de este volumen para confirmarlo.17

I4 No creo que sea necesario acarrear aquí pruebas de la orientación científica de su pensamiento ni de sus omnívoras lecturas; son bien conocidas las diversas facetas de la multiforme mentalidad lugoniana: lector voraz, sobre temas variadisimos, marcada tendencia hacia la verificación experimental, insistencia casi obsesiva en elementos tan dispares como la lógica y claridad expresiva por un lado y el afán de decirlo todo en formas nuevas y sugestivas, rehuyendo tenazmente la región del lugar común por el otro. Para redondear la visión hay que agregar a estas condiciones del escritor-pensador las actividades tan o más diversas y agotadoras aun del funcionario público. Con todo, hubo tiempo para el bienvenido intervalo que Lugones pudo dedicar a una obra de deleite personal sobre un tema predilecto, obra que por consiguiente resulta una de las que más satisface desde el punto de vista estético y que más cabalmente revela una tendencia de la fuerza creadora del autor distinta, aunque no menos auténtica, de la que se luce en $\mathrm{La}$ guerra gaucba o en el Lunario sentimental, tendencia que, a juzgar por Las fuerzas extrañas, supone fusión más perfecta de materia y forma.

15 Borges (Leopoldo Lugones, pp. 71-72), refiriéndose a algunos cuentos de esta colección, afirma que "Estas páginas se encuentran entre las más logradas de las literaturas de lengua hispana". Guillermo Ara (Leopoldo Lugones, Buenos Aires, Editorial La Mandrágora, 1958, pp. 179-180), cuya reacción ante Las fuerzas extrañas parece ser en general indiferente, abserva, de todos modos, que Lugones posee dominio de la técnica narrativa y menciona de paso dos hechos importantes: que Lugones es uno de los iniciadores de la ficción científica en Hispanoamérica y que influye en cuentistas posteriores como Borges y Bioy Casares. Emma Susana Speratti Piñero también reconoce en Lugones un iniciador ("La expresión de las 'fuerzas extrañas' en Leopoldo Lugones", p. 2).

16 Se entiende que la voz del Lugones de los cuentos cientificistas quedara más o menos amortiguada ante el clamor de los acontecimientos de su multiforme vida pública; también se entiende, entre las otras consecuencias de este hecho, el tardío reconocimiento del valor de Las fuerzas extrañas. Borges, que todo lo sugiere y lo deja para que otros entren luego en pormenores, ha observado que en Lugones el artista es siempre más convincente que el filósofo, que "sus razones casi nunca tenían razón; sus epítetos, casi siempre" (Leopoldo Lugones, p. 83). En este sentido, y no el arbitrario y generalmente ambiguo de las filiaciones de escuela o movimiento literario, sí es lícito hablar de dos Lugones, uno polémico cuyo propósito es más bien intimịdar que convertir al lector, en que abundan las generalizaciones y simplificaciones - Borges recuerda que Lugones "postulaba una diferencia moral entre el recurso métrico de repetir determinadas sílabas (rimar) y el de no repetirlas" (loc, cit.) - y otro, que ha de interesarle mucho más desde luego a la posteridad, y que debemos buscar en las páginas "no maculadas de polémica", según la frase de Borges, como la Historia de Sarmiento, El Payador, o algún admirable cuento fantástico.

17 Hay que tener presente que hacia 1900 su labor empieza a ser reconocida. El padrinazgo de Groussac y el rotundo aplauso de Dario a sus primeros trabajos 
A fin de hacer un análisis más comprensivo de Las fuerzas extrañas se invertirá el orden en que está presentado al lector; es decir, se examinará primero el "ensayo de una cosmogonía" y luego los cuentos con que se inicia. Efectivamente, se comprenden mejor los relatos en función de dicho tratado cosmogónico porque a pesar de estar expuesto como otra historia ficticia, en el fondo no es otra cosa que la concepción lugoniana del universo, su visión metafísica. Muchas otras particularidades de su poesía y de su pensamiento en general cobran sentido cuando se las refiere a esta manera de concebir el mundo y el universo. Esto no quiere decir que sea menester tomar al pie de la letra el ensayo; hay que tener en cuenta que no se trata de la expresión sistemática de un filósofo, sino de la filosofía de un poeta, o sea que tiene una considerable dosis de imaginación, de intuición poética ajustada, por una mente analítica, a principios científicos de extraordinario rigor. Lugones estaba al día con respecto al pro-

le valieron la consideración de los hombres de gobierno. Fue designado, aunque no detentaba título académico alguno, Visitador de Enseñanza Secundaria, Normal y Especial. En esta capacidad Lugones recorrió el país en actitud de fervorosa curiosidad, compenetrándose de los problemas y fallas de la educación secundaria argentina. De sus observaciones surgió el tratado La reforma educacional, publicado en 1903. libro polémico cuyas ideas pedagógicas provocaron virulentos ataques por parte de los educadores profesionales. Mientras fue Visitador y más adelante Inspector General de Enseñanza, aprovechó para estudiar con cierto método, pues debía seguir el camino gradual de los programas escolares, casi todas las disciplinas científicas, en las que adquirió un conocimiento más que adecuado para su función. Efectivamente, en ciertas disciplinas, como la química, la geología y las matemáticas, alcanzó inesperada pericia. El año siguiente hizo su primer viaje fuera del país, como representante de la Argentina al Congreso Científico Latinoamericano que se celebró en Montevideo. Pocos meses después fue comisionado por el gobierno a otra labor cultural que le llenó de satisfacción, pues le permitió bucear en el pasado argentino, en las tradiciones y en el desarrollo histórico de la cultura hispánica. Su misión consistía en estudiar sobre el terreno, las ruinas de las misiones jesuíticas, en un deseo de salvar del olvido un importante período histórico del Noreste argentino. En un año tenía redactado ya su informe, que se publicó en 1904 con el título El Imperio Jesuitico. La obra fue mucho más allá de la simple memoria; es un excelente ensayo histórico en que Lugones penetró en el pasado, armado de su propia concepción histórica, e interpretó de una manera nueva el papel de la Compañia de Jesús en la colonización americana. 1905 fue uno de los años nnás fecundos, entregando el autor a las prensas dos de sus obras más notables, La guevia gaucha y Los crepúsculos del jardin. El escritor de treinta y un años escasos, publicó casi simultáneamente dos obras que son orgullo de la literatura argentinat, un libro de versos, de plenas resonancias simbolistas y otro de narraciones épicas, donde el autor, por otra típica incongruencia, borda en un estilo a la vez viril $y$ artificioso, un prodigioso encaje barroco, hasta lograr que el idioma alcance una sonoridad insólita, como si naciera un nuevo romance en que el lector cree reconocer raices y vocablos para luego descubrir que significaban otra cosa. En 1906 Lugones se dedica nuevamente a la misma labor pedagógica que había iniciado tres años antes, emprendiendo el primero de varios viajes que hizo a Europa, con el encargo del gobierno de estudiar los principales sistemas educacionales. 
greso de la ciencia en diversos campos, especialmente en física, química y biología.

Leyendo este ensayo de cosmogonía se pueden inferir las especulaciones ontológicas de Lugones y sus esfuerzos por resolver problemas científico-filosóficos, esfuerzos infructuosos, desde luego, debido entre otras cosas a la intransigencia de su espíritu corrosivamente lógico.

\section{CIENCIA}

El orden expositivo del ensayo lugoniano no es el de sus propias reflexiones, sino el orden lógico, que hará más fácil la comprensión del lector. La primera lección se titula "El origen del universo" (págs. ${ }^{777-}$ I8I), pero las ideas alli expuestas presuponen una especulación previa que aparece desarrollada más adelante, y que forma en suma, el tema central de su pensamiento. La teoría presentada a lo largo de las diez lecciones puede sintetizarse así: la materia no fue creada de una vez, sino por grados. La primera manifestación es todavía un elemento sin dimensión, sin peso, sin ninguna de las cualidades típicas de la materia en sus formas más avanzadas. Esta primera manifestación es algo así como los rayos gamma de reciente descubrimiento en tiempos de Lugones. El tipo de electricidad que contienen es estática y se propaga en una sola dirección, es decir, es una energía rectilínea. Al ponerse en movimiento generan el espacio porque estos rayos, sin resistencia y sin solicitudes tienden a revolver sobre sí mismos, engendrando la curva, y al cerrarse ésta, nace la superficie, o sea, la segunda dimensión. La próxima escala del proceso evolutivo es la introducción del tiempo. Hasta este momento la energía absoluta ha carecido por completo de tiempo, siendo pura eternidad. La tercerá dimensión es producida por la revolución de un plano sobre su eje: los círculos que crea el primer rayo lineal engendran, al girar por efecto de rozamientos tangenciales, Ia esfera. Dentro de dichas esferas se inscriben poliedros, productos a su vez de los polígonos de energía que estaban inscriptos en el círculo original. Con la transformación de estos poliedros en átomos se crean lo que el autor llama "centros de fuerza individualizada" (Cuarta lección: "Los átomos", págs. r88-r93).

Posteriormente surgen los otros fenómenos inherentes a la materia, ya constituida de sus cualidades conocidas: el calor, en primer lugar, resultado de la fricción interatómica. La fricción produce además, desgaste y creación de nuevos átomos por fusión de los anteriores y debido a la gran temperatura la materia se condensa, dando lugar a sucesivas reacciones 
químicas. El calor, la luz, el sonido y hasta el olor, son otras tantas manifestaciones de la radioactividad, o energía infinita, sin espacio ni tiempo.

De este movimiento atómico perpetuo se produce eventualmente un equilibrio de masas, una igualdad de tensiones que da por resultado la gravedad. "La materia es, si se tiene esto en cuenta, electricidad neutra cuya tensión se ha transformado en gravedad" (Sexta lección: "La vida de la materia", págs. 20r-205).

Cuando un planeta ha organizado su materia en tres estados: gaseoso, líquido y sólido, empieza el proceso de desintegración que dura tanto como el que empleó en formarse. Este movimiento cíclico constituye la ley de la periodicidad. Tan pronto como la materia ha evolucionado hasta los tres estados referidos, ocurre "la aparición de los seres orgánicos" (Séptima lección: "Los elementos terrestres", págs. 206-208).

Según esta teoría de Lugones no hay diferencia entre la materia orgánica y la inorgánica, como no hay diferencias entre materia y energía ni entre tiempo y espacio, en lo esencial. Esto presupone que tampoco hay diferencias entre materia y espíritu, y las lecciones subsiguientes están dedicadas a explicar este punto, quizá el más decisivo en la "cosmogonía" de Lugones, y por la cual se explican los cuentos que la preceden en Las fuerzas extrañas.

Siendo la materia idéntica, hay sensibilidad en los metales, o en los gases, como en los seres vivos. Las afinidades químicas, o el mimetismo animal, o los fenómenos fotosintéticos de las plantas, son expresión de la sensibilidad de la materia. La vida orgánica proviene de la atracción de elementos heterogéneos que en un momento dado produjeron el nacimiento de la vida, aunque en un sentido muy diferente todavía al que tiene para el hombre moderno. Todas estas transformaciones obedecen a un pensamiento inteligente, que según Lugones, está implícito o latente en cualquier forma de la materia, ya sea en la cristalización de las rocas o en las combinaciones moleculares. "El pensamiento es una forma de la energía", dice el autor (Novena lección: "La inteligencia en el universo", pág. 215) y añade más adelante:

Todas las manifestaciones de la vida son formas de pensamiento, puesto que lo son de la energía absoluta en su eterno doble trabajo de integrarse y desintegrarse. ${ }^{18}$

18 Las fuerzas extrañas, p. 216. 
Sin embargo, este pensamiento no es Dios, según la explicación de las religiones. Tampoco acepta el autor la explicación panteísta. No existe una inteligencia fuera del espacio y el tiempo; tampoco es esa inteligencia omnipotente ni omnisciente, como lo prueban los experimentos fracasados en los diversos reinos, los cataclismos celestes y otros:

Si hubiera un Creador omnisciente y omnipotente, el universo sería una máquina perfecta, sin ningún tropiezo posible. ${ }^{19}$

Todo sonido, toda luz, todo color, son:

trabajos de desintegración de la materia, y toda percepción inteligente de estos fenómenos es reintegración de materia a la energía absoluta. ${ }^{20}$

Hasta aquí Lugones ha rechazado muchos postulados de la teoría de Laplace y ha aceptado la de Darwin. Pero al tratar la aparición del hombre y los animales evolucionados, se aleja de la idea darwiniana en el sentido de que, siendo el hombre la expresión superior de la vida, es decir, equilibrio entre materia y pensamiento, con capacidad para pensarse a sí mismo, Lugones sostiene que el hombre aparcció antes que los otros animales, y que la escala de Darwin ocurrió efectivamente; pero al revés: "El hombre es, pues, el progenitor del reino animal" (Décima lección: "El hombre", pág. 224). De ahí que el Génesis diga que Adán "da nombre" (nota 2, pág. 224) a los habitantes de la tierra, lo que en sentido metafísico viene a significar que los engendtó por acción mental, que "pensó" (pág. 224) su descendencia y que, por medio del verbo, los hizo reales. Lugones apoya esta teoría en múltiples verdades científicas que demuestran que las demás cspecies no pudieron preceder al hombre sobre la tierra.

Para completar esta síntesis del ensayo lugoniano, sólo resta decir que este proceso se repite en diversos lugares del universo. Todo es un fenómeno de conversión de la energía en miteria; la materia, al llegar a su máximum de estabilidad (el estado sólido) "inicia el proceso inverso, o de desintegración, y los seres van tendiendo a convertirse en focos de eterización cada vez más activa" (Décima lección: "El hombre", pág. 223). 
El ensayo final recoge y sintetiza en teoría general las varias hipótesis científicas que sirven de base a los doce relatos que lo preceden. Veamos ahora, en forma esquemática, cómo las ideas del ensayo se convierten en cuentos cientificistas y como las fuerzas extrañas empiezan a adquirir vigencia paralela, casi equivalente en realidad, a las científicas. Una lectura detenida de "La fuerza omega" (págs. 9-24), por ejemplo, - "La metamúsica" (págs. 79-93), y más que nada "El origen del diluvio" (págs. 97-I05), revela que estos cuentos están basados en las mismas especulaciones explicadas en forma sistemática en el ensayo:

En "La fuerza omega" el curioso investigador, partiendo de la hipótesis de que el sonido es parte volatilizada de la materia, logra la desintegración atómica por medio del bombardeo de ondas sonoras. Recuérdese que en el ensayo se afirma que el sonido es una manifestación de la energía absoluta; energía y materia son una misma cosa puesto que una engeridra a la otra.

"La metamúsica" trata nuevamente el concepto de la identidad de la materia, pero ahora el excéntrico músico que protagoniza el cuento trata de hacer perceptibles los colores del sonido, basándose en la hipótesis de que las vibraciones sonoras y luminosas son de la misma naturaleza y que hay una proporción matemática entre ambas. Lo que las hace distintas es la capacidad sensorial del observador; cuando el oído no alcanza a percibir ciertas ondas, éstas se manifiestan como color, y viceversa.

El protagonista de la narración titulada "El origen del diluvio" es un espíritu. No hay, pues, anécdota, al menos humana, sino la evocación que este espíritu hace de los orígenes del planeta. Estas evocaciones tienen una íntima correspondencia con el ensayo, pues desarrollan, ampliándolas extensamente, las ideas expresadas allí. El relato empieza cuando la tierra "acababa de experimentar su primera incrustación sólida" (pág. 97). Se describen las primeras formas vivas, animales y vegetales; la presencia de ciertos elementos químicos, su refracción atmosférica en forma de colores, las alotropías "disparatadas" de aquel planeta que estaba ensayando la creación, y por fin, la verdadera naturaleza del diluvio y la función que vino a cumplir. De la vaporización de los mares de la luna ocurrió el fenómeno que llamamos diluvio por efecto de la gravedad terrestre. Este diluvio trajo a la tierra cuerpos químicos inexistentes hasta entonces y provocó la desaparición de la vida anterior en la tierra, a causa de las "formidables tempestades químicas" (pág. I0z) que desató. Pero por otra parte, viajando por el cono de sombra de la luna, llegaron "gérmenes vivificantes" (pág. I03) que transportaron la vida del planeta 
viejo al nuevo, renovando el eterno proceso expuesto también en el ensayo teórico.

"Viola acherontia" (págs. I2I-I29), "Yzur" (págs. I33-I44) y "El psychón" (págs. I57-I69) también son fábulas basadas en esa cosmogonía. En el primero de estos relatos, se presenta nuevamente la idea de que la inteligencia, como forma de la energía absoluta, puede encontrarse en las plantas. Las leyes de la herencia, que serían una forma de esa inteligencia universal, permiten lograr una especie de violetas asesinas a lo largo de una serie de cruzamientos y exposición a diversos ambientes fúnebres y malvados. En "Yzur" se intenta demostrar que los monos fueron antes seres humanos, en contra de la teoría de la evolución que supone al hombre descendiente del mono, idea que también se ha desarrollado en el "ensayo de una cosmogonía".

Finalmente, en "El psychón", el autor desarrolla en forma de cuento su propia teoría de que el pensamiento es una forma de materia. El sabio de este relato busca materializar el pensamiento, a base de los impulsos eléctricos del cerebro. En seguida transforma estos tenues impulsos en líquido, siguiendo un procedimiento reciente en la química para incrustarlo finalmente en alguna pieza metálica, fundiendo así "medallas psíquicas".

\section{FICción}

Hemos visto hasta aquí el esqueleto científico y paracientífico de Las fuerzas extrañas; la ecuación de Moore está, pues, a medio resolver. Veamos ahora cómo Lugones maneja los elementos de que depende todo aquello para transformarse en una espléndida obra literaria.

Las fuerzas extrañas se manifiestan de diversas maneras, en armonías insospechadas entre los números y ciertas leyes universales ("La metamúsica"), en cualidades misteriosas, y no siempre privativas, del espíritu y de la materia ("El psychón", "La fuerza omega", "Viola acherontia") y en analogías constitutivas entre colores y sonidos ("La metamúsica").

En "La fuerza omega" por ejemplo, se proyecta una concepción microcósmica de la mente humana, siendo ésta esencialmente idéntica a las fuerzas directrices del universo y esperando sólo -en esto se advierte el influjo de las ciencias y filosofías ocultas- la abolición de obstáculos como la materia, ya que el tiempo y el espacio "los dos conceptos fundamentales, los más fundamentales como realidad y como obstáculo" (pág. 
I0), los franquea la mente humana mediante el uso de la memoria. Es éste un notable ejemplo del proceder lugoniano en la concepción y el tratamiento ficcional de las fuerzas extrañas. El vuelo imaginativo del autor concibe el ejercicio de la memoria como una superación, que luego traduce en "conquista" del tiempo y del espacio; lo comprueban su capacidad para:

evocar instantáneamente un lugar que se vio hace diez años y que se encuentra a mil leguas; para no hablar de ciertos casos de bilocación telepática, que demuestran mejor la teoría. ${ }^{21}$

El extraño jardinero de "Viola acherontia" supone que en las plantas hay el poder de recibir y conservar una impresión. Sobre este tema se ejercita la estupenda ingeniosidad lugoniana:

Según él [el jardinero] la marcha de los vástagos en las enredaderas, obedecía a una deliberación seguida por resoluciones que daban origen a una serie de tanteos. De aquí las curvas y acomodamientos, caprichosos al parecer, las diversas orientaciones y adaptaciones a diferentes planos, que ejecutan las guías, los gajos, las raíces. Un sencillo sistema nervioso precedía esas obscuras funciones. Había también en cada planta su bulbo cerebral y su corazón rudimentario, situados respectivamente en el cuello de la raíz y en el tronco. La semilla, es decir el ser resumido para la procreación, lo dejaba ver con toda claridad. El embrión de una nuez tiene la misma forma del corazón, siendo asaz parecida al cerebro la de los cotiledones. Las dos hojas rudimentarias que salen de dicho embrión, recuerdan con bastante claridad dos ramas bronquiales cuyo oficio desempeñan en la germinación. ${ }^{22}$

Maravilloso tour de force ${ }^{23}$ de la imaginación cientificista del autor en que se van hilvanando, en progresión deslumbrante, los más penetrantes hallazgos paracientíficos cuyo interés se debe, más que a la novedad o sorpresa, a la sutil derivación científica y a la irresistible lógica de su elaboración.

21 Ibid, pp. 10-11.

22 Ibid, pp. 121-122.

23 Podrían citarse en este sentido también el increible malabarismo numérico de "La metamúsica (pp. 90-91), la descripción de "los gigantes de que hablan las leyendas" en "El origen del diluvio" (p. 98), la del "psychón" y el aparato que lo engendra (pp. 166-168), etcétera. 
Como se habrá observado en los pasajes reproducidos anteriormente, el estilo de estos relatos se distingue más por su claridad ${ }^{24}$ y precisión que por la habitual suntuosidad lugoniana. Los efectos estilísticos tales como aparecen aquí están logrados consistentemente y siempre dentro del tono general de la narración, sin errupciones de virtuosismo o piruetas intrusas. Hay elegancia metafótica, que de vez en cuando recuerda el lujo verbal de otras obras del autor, pero nunca llega a la ocasional aparatosidad de aquéllas porque las imágenes resultan funcionales, en la gran mayoría de los casos, contribuyendo directamente a la tensión progresiva de la narración, sin quedar reducidas a la calidad de adornos superfluos. La expresión metafórica y la fértil invención temática del cuentista se emplean en Las fuerzas extrañas con un grado de destreza y disciplina mayor quizá que en cualquier otra obra en prosa del autor; dichos recursos están reservados para el momento preciso de la narración en que su efecto se hace sentir con el máximum de intensidad. Muy lejana en este sentido esta colección de cuentos del sofocante bosque de metáforas y materia léxica que es La guerra gaucha. A diferencia de la excursión metafórica en que el desfile implacable de imágenes llega a anular su efecto individual, en Las fuerzas extrañas los recursos estilísticos apoyan y se funden al tono general de la narración sin quedar sueltos como objetos de exhibición.

Las refundiciones de temas bíblicos y legendarios presentan un estilo mucho más complejo y variado que los relatos estrictamente cientificistas ${ }^{25}$ en aquéllas la creación de tono y ambiente trae una mayor penetración del verso en la prosa: expresión metafórica (en "La lluvia de fuego" el granizo incandescente caía "en trozos de cobre que vibraban como el cordaje innumerable de un harpa" [pág. 35], los leones "enloquecidos de cataclismo" llegaron "en una desproporción de cómicos a medio vestir" [pág. 39], el viento que se cuela por la ciudad en escombros es "ardentísimo, denso, como alquitrán caliente" [pág. 36]; en "El milagro de san Wilfrido" la figura del santo crucificado aparece como "una escarcha fina sobre un mármol artístico" [pág. 65], y más

24 A propósito del estilo de Las fuerzas extrañas, Juan Carlos Ghiano dice (Lugones escriton. Notas para un análisis estilistico, Buenos Aires, Editorial Raigal, 1955, p. 75): "lo fantástico del tema mitológico está desarrollado en el sentido clásico de la estructura narrativa, a la vez que en claridad nitida del lenguaje".

25 Antonio Pagés Larraya (20 ficciones argentinas, p. 8) se refiere a las diferencias estilísticas que se advierten entre los distintos tipos de relato: "Precisamente algunos de los relatos se despojan de todo ornamento para acentuar la impresión científica; en otros, la suntuosidad expresiva toca límites de prodigio... En otros la destreza verbal se despliega para conseguir efectos repulsivos o para precisar con lujo de minucias todo el alcance de la idea". 
adelante, "un vaso de alabastro que ha dejado correr todo su vino" [pág. 66], "bajo sus párpados entreabiertos, se vislumbraba una minúscula estrella azul"' (pág. 66), efectos acústicos, colorismo, aliteración, relativa riqueza léxica, $y$ en general un tono más enfático y macizo.

Se debe tener en cuenta, sin embargo, que éstas son instancias más o menos aisladas, que el conjunto de material ornamental es en realidad mínimo en esta obra, sobre todo si se lo relaciona con la prosa de $L a$ guerra gaucba, y que en Las fuerzas extrañas lo principal en cuanto al estilo es la precisión y la economía en el empleo de elementos decorativos.

El horror lugoniano tiene aspectos muy especiales aunque no del todo desconocidos al lector de su poesía. La fórmula suele basarse en el entrelazamiento de varios matices cuya eficacia reside frecuentemente en su sutileza y trivialidad. Se busca típicamente el efecto desolador, el estremecimiento escalofriante; un diminutivo perfecto: "partículas de cobre incandescente que daban en el suelo con un ruidecito de arena" (pág. 27), "Una rapidísima vírgula de fuego, y el golpecito en la tierra. Así, a largos intervalos" (pág. 28), ${ }^{26}$ algún detalle trivial, que no por serlo deja de sacudir al lector, como aquel en que se describe la primera consecuencia perceptible de la lluvia mottal: "El cielo seguía de igual limpidez; el rumor urbano no decrecía. Unicamente los pájaros de mi pajarera, cesaron de cantar" (pág. 27). La fuerza sugestiva de los relatos está reforzada con antítesis temáticas como la casi monótona insistencia en la limpidez del cielo que hace más espantosa la llovizna de fuego: "El aire, rayado de vírgulas de fuego, era de una paralización mortal; y por entre aquéllas, se divisaba el firmamento, siempre impasible, siempre celeste" (pág. 34) y violentos contrastes de ambiente entre los cuales los más marcados son el que se establece en "La lluvia de fuego" entre el clamor de la ciudad condenada, por un lado, y el silencio de la cisterna subterránea en que se refugia el protagonista por el otro, y el contraste luz-oscuridad que surge, en el mismo relato, cuando el sol al declinar se pierde en humo y polvareda, dando lugar a la lucha pavorosa entre las tinieblas y el fuego:

26 En "El escuerzo" salta a la vista este otro par de instancias:

la luna muy baja empezaba a bañar con su luz el aposento cuando de repente un bultito negro [el sapo vengativo], casi imperceptible, saltó sobre el dintel de la puerta (p. 75 ).

Aquella figurita lúgubre, inmóvil en la puerta llena de luna, se agrandaba extraordinariamente, tomaba proporciones de monstruo (p. 75). 
Parecia que se estuviese en un inmenso horno sombrio. Cielo, tierra, aire, todo acababa. No había más que tinieblas y fuego. Ah, el horror de aquellas tinieblas que todo el fuego, el enorme fuego de la ciudad ardida no alcanzaba a dominar. ${ }^{27}$

No es el convencional horror sangriento, o de la muerte como tal, o de la crueldad, sino la estupefacción paralizante en la presencia de fuerzas incontrolables y desconocidas, "las fuerzas extrañas" efectivamente. Los animales y las flores hacen un papel importante en la creación de efectos de horror, ya que "El alma sucinta de la bestia agregaba a sus terrores de muerte, el pavor de lo incomprensible" (p. 40). La falta de comunicación entre los hombres y los animales aparece en los cuentos de Lugones como clave de toda una serie de "fuerzas extrañas" que se hacen visibles tan pronto como se introduce algún desequilibrio o alteración en la armonía natural de su existencia. En "Los caballos de Abdera" los seres humanos, al estorbar caprichosamente el ritmo vital de los animales desatan fuerzas extrañas que no pueden controlar y cuyas consecuencias catastróficas, tan imprevistas como inesperadas, se vuelven sobre ellos y los destruyen. En este caso es la siniestra humanización de los caballos, realzándose siempre en la agitada descripción lo monstruoso de aquella rebeldía pervertida. Están a tal punto entrelazados el tremendismo de la descripción, lo macabro y el humor convulsivo que por momentos el lector se balancea entre el estupor y la carcajada. El autor nos describe una bestia mimada que "había exigido espejos en su pesebre" y, una vez concedido el capricho, "daba muestras de coquetería perfectamente visible" (pág. III), un bello potro sentimental que "tenía dos campañas militares y manifestaba regocijo ante el recitado de exámetros heroicos" y que "acababa de morir de amor por una dama" (pág. III I), y así en espeluznante y monstruoso crescendo:

hasta se señalaba una noble doncella que sollozando narraba entre dos crisis su percance: el despertar en la alcoba a la media luz de la lámpara, rozados sus labios por la innoble geta de un potro negro que respingaba de placer el belfo enseñando su dentadura asquerosa; su grito de pavor ante aquella bestia convertida en fiera, con el resplandor humano y malévolo de sus ojos incendiados de lubricidad; el mar de sangre con que la inundara al caer atravesado por la espada de un servidor . . .28 
La fecundidad inventiva y la pericia del narrador se manifiestan con toda claridad en la confección y en el manejo de las tramas, siempre variadas e ingeniosas. Las hay más o menos lineales ("El escuerzo", "La estatua de sal"), ${ }^{29}$ en que la acción es concisa y se precipita directamente al desenlace, junto a otras de más compleja organización en que se advierte una progresión dramática del conjunto ${ }^{30}$ basada en tensiones y distensiones, en un movimiento pendular a través de la narración entre la gravedad del cuerpo del relato y la ligereza de ciertos momentos de relajamiento en el suspenso o en alguna sorpresa final deliberadamente trivializada. En "La lluvia de fuego" se funden la ligereza de ciertas descripciones o caracterizaciones, como la del protagonista del cuento cuyas excentricidades están descritas en un tono de humor realista: "Excepto la biblioteca, el comedor era mi orgullo. Ahito de mujeres y un poco gotoso, en punto a vicios amables nada podía esperar ya sino de la gula" (pág. 28) y la tremenda gravedad de la historia: "El esclavo que atravesaba el jardín... tenía en su desnuda espalda un agujerillo, en cuyo fondo sentíase chirriar aún la chispa voraz que lo había abierto" (pág. 29). La interacción de contrastes como el anterior está tan hábilmente manejada que no se interrumpe el fluir de la narración, ni hay dejo alguno de detalles retocados.

En "El escuerzo", fábula más sobrenatural que cientificista, se refunde la vieja leyenda del sapo que, a menos que se queme el cadáver tan pronto como haya muerto, resucita y se venga violentamente del que lo mató. La versión lugoniana, aun tratándose del relato más insignificante de la colección, se salva por esta terminación macabra: el sapo se ha colocado de un salto en la caja en que duerme su víctima; la madre de éste también muere del espanto que le produjo lo que vio al abrirla:

Un frío mortal salía del mueble abierto, y el muchacho estaba helado y rígido bajo la triste luz en que la luna amortajaba aquel despojo sepulcral, hecho piedra ya bajo un inexplicable baño de escarcha. ${ }^{31}$

29 Según Emma Susana Speratti Piñero, "La estatua de sal" es la narración más lograda del libro. Elogia sobre todo su "parquedad apretada", es decir la intensidad dramática creada sin excesos verbales, y el desenlace enigmático e inquietante ("La expresión de las 'fuerzas extrañas' en Leopoldo Lugones", pp. 13 . 16).

30 La señora Speratti Piñero opina que Lugones tiende a sobrecargar de retórica cientificista algunos relatos," ahogando "casi por completo la virtud del narrador" (obra cit., p. 2).

31 Las fuerzas extrañas, p. 76. 
A propósito del desenlace, elemento decisivo en la técnica de todo cuentista, sobre todo los modernos en cuya concepción del relato corto el efecto final se ha convertido en algo así como la razón de ser del cuento, a Lugones hay muy pocos que le aventajan. En los relatos cientificistas es frecuente que la resolución de un problema científico o la demostración crucial de algún experimento traiga como consecuencia la destrucción violenta del investigador, revelándose a último momento algún aspecto anteriormente desconocido de la fuerza extraña específica cuyas características se intentaba descubrir. La técnica no es nueva, desde luego, habiéndose utilizado más que cualquier otra seguramente en los varios génetos de ficción científica desde Jules Verne en adelante. En Lugones se hallan además, superpuestos a esta configuración final del relato varios efectos y matices emotivos, entre los cuales uno de los más típicos es el remate humorístico, a veces ligeramente irónico. La fuerza "omega" del primer cuento, que sólo su descubridor sabe activar, acaba convirtiéndose en mortífero proyectil que por algún descuido, se supone, le ultima:

la pared a la cual casi tocaba la cabeza del muerto, se hallaba cubierta de una capa grasosa, una especie de manteca... ¡Esto es sustancia cerebral!... Ni un rastro exterior denunciaba la catástrofe, y aquel fenómeno, con todo su horror, era, a fe mía, el más estupendo de cuantos habíamos presenciado... En el instituto Lutz y Schultz han ensayado también sin éxito. ${ }^{32}$

En la magistral página final de "El psychón", Lugones extrema el procedimiento, animando la narración de un desenfrenado humor burlesco. El doctor Paulin ha descubierto el método de volatilizar el pensamiento, pero sucede que por casualidad la forma espiritual que le toca transformar al ingenioso investigador es nada menos que el elíxir de la locura:

De pronto noté en la cara del doctor una expresión sardónica enteramente fuera de las circunstancias; y casi al mismo tiempo, la idea de que seria una inconveniencia estúpida saltar por encima de la mesa, acudió a mi espíritu; mas, apenas lo hube pensado, cuando ya el mueble pasó bajo mis piernas, no sin darme tiempo para ver que el doctor arrojaba al aire como una pelota su gato, un siamés legítimo, verdadera niña de sus ojos. El cuaderno fue a parar con 
una gran carcajada en las narices del doctor, provocando por parte de éste una pirueta formidable en honor mío. ${ }^{33}$

Años pasan sin que nada se sepa del simpático doctor Paulin; por último el narrador se entera de que "ha repetido su experimento, pues se en" cuentra en Alemania en una casa de salud" (pág. r69)..$^{34}$

No menos inolvidable es el desenlace entre repulsivo e irónico de "Viola acherontia" fábula en que, como hemos visto, a un viejo jardinero se le ocurre experimentar con mutaciones celulares y extravagantes procedimientos asociativos para crear "la flor de la muerte", siendo el primer paso el obtenimiento de una violeta negra, con lo cual "estaba conseguida la primera nota fúnebre" (pág. x25). El macabro proceso de sugestión floral continúa hasta que se advierte que "aquellas flores se quejaban en efecto, y de sus corolas obscuras surgía una pululación de pequeños ayes muy semejantes a los de un niño" (pág. I28). La sugestión se ha operado en efecto, pero por un camino inesperado: "aquellas flores no hacian sino llorar" (pág. I28). De pronto se acuerda el narrador que la mandrágora también llora cuando se la riega con sangre infantil:

$Y$ nunca hemos vuelto a vernos. Pero mi convicción de ahora es que se trata de un verdadero bandido, de un perfecto hechicero de otros tiempos, con sus venenos y sus flores de crimen. ¿Llegatá a producir la violeta mortífera que se propone? ¿Debo entregar su nombre maldito a la publicidad?... ${ }^{35}$

Hacia el final de "La lluvia de fuego", cuando la ciudad está ya casi carbonizada, momento culminante del cuento, en que, de no terminarlo ahí, el autor habría podido incurrir en un lamentable anticlímax, nos presenta uno de los espectáculos más escalofriantes de la obra, ${ }^{36}$ la carrera vertiginosa de un tropel de leones rabiosos:

33 Ibid, p. 169.

34. El mismo tono jocoso anima todo el relato, no sólo el desenlace. Recuérdese el regocijo con que se nos cuenta la analogía entre la tonsura de los monjes, que se rapaban para dejar surgir ciertos fulgores divinos, y el polo norte del mundo del que también emanan fulgores y que es por consiguiente, "algo así como la coronilla del planeta" (p. 162).

35 Las fuerzas extrañas, p. 129.

36 ¿Qué prodigios habría inventado la imaginación lugoniana hoy, con el fértil horizonte de posibilidades que le hubieran proporcionado los adelantos de los últimos años en materia de armas atómicas y viajes interplanetarios? Sin duda le habría fascinado especialmente el ya familiar tema de la exterminación de la raza humana, brotando un sobreviviente que otro de alguna cueva para enfrentarse con vastos desiertos de ceniza radioactiva. Efectivamente, en "La lluvia de fuego" 
Pelados como gatos sarnosos, reducida a escasos chicharrones la crin, secos los ijares ... el rabo agudo y crispado como el de una rata que huye, las garras pustulosas, chorreando sangre - todo aquello decía a las claras sus tres días de horror bajo el azote celeste... sentándose por último ... con el calcinado hocico en alto, la mirada vagorosa de desolación y de eternidad, quejándose al cielo, estoy seguro, pusiéronse a rugir . . . Ah . . . esos rugidos, lo único de grandioso que conservaban aún aquellas fieras disminuidas: cuál comentaban el horrendo secreto de la catástrofe; cómo interpretaban en su dolor irremediable la eterna soledad, el eterno silencio, la. eterna sed . . .37

En este maravilloso relato se hallan muchos de los recursos temáticos y estilísticos más característicos del libro (recursos de que, dicho sea de paso, no es posible dar idea cabal transcribiendo trozos aislados): humanización de la naturaleza y de los animales, frecuente en toda la obra como se ha demostrado ("Yzur", "Los caballos de Abdera", "Viola acherontia", "Un fenómeno inexplicable", "La lluvia de fuego"), lenguaje grandioso, elegante y preciso a la vez, creciente dramatismo que hace parecer inagotable la capacidad del autor para inventar, tras cada momento de tensión, otro más dramático aún.

En "Yzur" el desenlace es de un patetismo verdaderamente desgatrador. El investigador explica -es el único relato de tipo cientificista en que la narración está hecha en primera persona- su intento, el de hacer hablar a un chimpancé para comprobar su teoría de que los monos fueron antes hombres que por una razón u otra dejaron de hablar. Tras largos e infructuosos experimentos que dejan en el lector, por primera y única vez en Las fuerzas extrañas, la impresión de un investigador más bien caprichoso que excéntrico, ${ }^{38}$ el animal llega al fin de su resistencia y amenaza

el autor toca directamente el tema, hasta el macabro detalle de que la salvación del individuo (se trata de "un piloto") se debe al haber matado a un compañero:

El sol brillaba inmenso, y aquella soledad empezaba a agobiarme con una honda desolación, cuando hacia el lado del puerto percibí un bulto que vagaba entre las ruinas. Era un hombre, y habiame percibido ciertamente, pues se dirigía a mí.

No hicimos ademán alguno de extrañeza cuando llegó, y trepando por el arco vino a sentarse conmigo. Tratábase de un piloto, salvado como yo en una bodega, pero apuñaleando a su propietario. Acababa de agotársele el agua y por ello salía (p. 38 ).

37 Las fuerzas extrañas, pp. 39-40.

38 Se advierte aquí algo muy cercano al fenómeno psicológico que Poe llama "the imp of the perverse"; al leer en "Yzur" que, pese a cietto temordimiento de 
con llevarse al otro mundo el secreto de las especies. Por fin el mono, en que ya "se había operado un gran cambio en su carácter... adoptaba posturas meditabundas ... había adquirido la costumbre de contemplar las estrellas... íbasele notando una gran facilidad de lágrimas" (pág. I39), se moría definitivamente:

y entonces, con su último suspiro, el último suspiro que coronaba y desvanecía a la vez mi esperanza, brotaron - estoy seguro-brotaron en un murmullo ( ¿cómo explicar el tono de una voz que ha permanecido sin hablar diez mil siglos!) estas palabras cuya humanidad reconciliaba las especies:

-Amo, Agua. Amo, mi Amo... ${ }^{39}$

El patetismo es también un elemento esencial en "La lluvia de fuego"; surge del contraste entre el pavor de la ciudad condenada y el afán de goce carnal que en tales circunstancias lo adquiere marcadamente como lo adquiere también la figura del triste protagonista que se aferra a sus comodidades domésticas: mientras el granizo mortal penetra en su casa, no puede menos de lamentar su siesta perdida y logra comer los restos de un pastel - mezcolanza típicamente lugoniana de lo pavoroso y lo trivial que aquí, como en otros cuentos de Las fuerzas extrañas, cuadra perfectamente con el tono y el efecto total de la narración. Lugones ha creado un admirable cuento de horror aprovechando todas las posibilidades que le ha sugerido el fascinante suceso bíblico de la destrucción de Gomorra.

Otra valiosa dimensión de Las fuerzas extrañas es que el autor ha universalizado, por decirlo así, algunos de sus relatos por medio de cierta ambigüedad de escena y realismo psicológico de los personajes - el de "La lluvia de fuego" es, como se recordará, un exquisito gourmet que además manifiesta una serie de graciosas excentricidades como la que, antes de llevarse a los labios el pomo de veneno, le impulsa a buscar nada menos que un trozo de jabón para darse el último baño. Hay múltiples detalles de la narración que les prestan al local y al tiempo del cuento una provocativa ambigüedad - en el mismo episodio se habla de vehículos, tráfico congestionado, jóvenes burgueses, libros, bibliotecas,

conciencia, en creciente irritación producida precisamente por el hecho de sentirse víctima del remordimiento--es decir, bastándole tan sólo pensar en que el experimento es algo sádico para que la obsesión de seguir con él se adueñe de su espiritu-el investigador azota cruelmente al infeliz mono, se piensa inevitablemente en "The Black Cat", "The Imp of the Perverse" y otros relatos del gran cuentista norteamericano.

39 Las fueqzas extrañas, p. 144. 
orquestas, campanas, iluminación caprichosa de la ciudad, petardos y otros anacronismos ${ }^{40}$ intencionales de este tipo que dejan en el lector la inequívoca sensación de encontrarse muy lejos de Gomorra, entre los patios, terrazas y toldos de Buenos Aires: ${ }^{41}$

Desde mi terraza dominaba una vasta confusión de techos, vergeles salteados, un trozo de bahía punzado de mástiles, la recta gris de una avenida ... d $^{42}$

Es posible, aunque no quisiera por ahora insistir demasiado en ello, ver más o menos oculta en varios pormenores del relato una especie de alusión satírica a la burguesía moderna, y si no fuera por la conocida detestación de Lugones por este elemento de la sociedad se lo podria afirmar con mayor seguridad y sin temor a leer demasiado entre las líneas. De todos modos, y valga o no el sentido de estas observaciones respecto de "La lluvia de fuego", creo que en el caso de "Yzur" ya no puede caber la menor duda de que el cuento tiene una dimensión análoga, satírico-sentimental en este caso, claramente diferenciada de su contenido cientificista. Emma Susana Speratti Piñero se refiere a "lo que muy rara vez se encuentra en Lugones: una veta de ternura", y añade que en los últimos párrafos del cuento se vierte "la emoción, tenue aunque evidente, hacia la solitaria angustia del irracional". 43 En cuanto al elemento satírico, "Yzur" está bien nutrido de alusiones ya de una sutil ironía, ya plenamente satíricas, dirigidas no a la burguesía sino al hombre racional, a cierto tipo de investigación científica, a la ciega y servil dependencia, para la solución de toda clase de problemas, sea lo que sea su naturaleza, en el método científico, y finalmente a aquellos individuos que para Lugones aparentemente equivalian a modernos eruditos a la violeta. Reproduzco sólo

40 Emma Susana Speratti Piñero opina que estos anacronismos le dan al lector la sensación de que "ese mundo pertenece más a la decadencia romana que a la antigüedad biblica y que se inspira voluntariamente en una Pampeya cercana". Añade que tales detalles "mortifican nuestra atención para el misterio hacia el cual se pretende arrastratinos ('La expresión de las 'fuerzas extrañas' en Leopoldo Iugones", p. 10). Es posible; pero a mi juicio la autora ha exagerado un poco el efecto de los anacronismos.

41 Análoga técnica narrativa, con propósito y expresión mucho más explí. citos, ocurte en la obra de Borges, como lo ha señalado Octavio Corvalán en una interesante nota ("Presencia de Buenos Aires en 'La muerte y la brújula' de Jorge Luis Borges", Revista Iberoamericana, Vol. XXVIII, Núm. 54, pp. 359363).

42 Las fuerzas extrañas, p. 27.

43 "La expresión de las 'fuerzas extrañas' en Leopoldo Lugones", p. 4. 
los ejemplos que me parecen más obvios, aunque la idea misma y el tono general del relato también lo confirman:

Trabajado por mi idea fija del lenguaje de los monos, agoté toda la bibliografía concerniente al problema, sin ningún resultado apreciable. Sabía únicamente, con entera seguridad, que no bay ninguna. razón científica para que el mono no bable. Esto llevaba cinco años de meditación. 44

Felizmente los monos tienen, entre sus muchas malas condiciones, el gtisto por aprender, como lo demuestra su tendencia imitativa. ${ }^{45}$ [Cierto sabio] hablaba de una "concatenación dinámica de las ideas", frase cuya profunda claridad honraría a más de un psicólogo contemporáneo. ${ }^{46}$

Los animales son perfectamente capaces del silogismo porque éste es:

originariamente una comparación entre dos sensaciones. Si no, ¿por qué los animales que conocen al hombre huyen de él, y no aquellos que nunca lo conocieron? ... ${ }^{47}$

Comentando la férrea tenacidad del investigador y su fe en que con persistir en su experimento llegará indefectiblemente al resultado deseado, el autor afirma que "el demonio del análisis ... impulsábame a renovar mis experiencias" (pág. $14 x$ ).

Hemos visto hasta dónde llega la fértil imaginación cientificista de Lugones, su dominio de la técnica del cuento (estilo, desarrollo de la trama, diversos efectos y matices) y también hemos tratado de demostrar que la eficacia de sus relatos se debe además a que tienen su origen en un conjunto de ideas orgánicas y relativamente claras; esto equivale a decir que se trata de una obra de valor universal. En este sentido es innegable que los cuentos de Lugones se mantienen solos. No es necesario extraer con cuentagotas sus excelencias de entre los primores estilísticos como lo es en algunas otras obras suyas. En Las fuerzas extrañas Lugones está pisando tierra firme, madurada en largas meditaciones, y felizmente, cuando llegó el momento de expresarlas en una obra literaria no se preocupó

44 Las fuerzas extrañas, p. 134.

45 Ibid, p. 135.

46 Ibid, p. 137.

si lbid, p. 138. 
gran cosa del estilo, ganando éste en fluidez y eficacia lo que perdió en lujo verbal. Incidieron, además, y no en forma despreciable, sus tempranos intereses en las ciencias ocultas. Perteneció a una generación impregnada de filosofía positivista, mecanicista, para la cual el universo, la materia, el espacio y sus leyes, tenían al fin explicaciones científicas, y al descubrir ciertos principios, los hombres de dicha generación, cegados por la nueva luz, se quedaron sin Dios, siendo ello parte del precio que pagaron por sus descubrimientos. Sin embargo, no siempre fueron suficientes para Lugones las explicaciones de la ciencia; tenía preguntas e inquietudes que ésta no podía resolver. Además, presentía la existencia de las "fuerzas extrañas" desde sus frecuentaciones a los clubes espiritistas, y desde sus lecturas juveniles en cuestiones de magia, astrología y filosofías orientales.

En el Lunario sentimental se nota que la visión de la luna es casi mítica, y que el libro está muy lejos de ser un simple capricho o juego de destreza. La influencia de la luna en las mareas y otros fenómenos, científicos o no, ejercían una poderosa sugestión en el poeta, y como lo demuestra $L a$ guerra gaucha, en que las descripciones de la naturaleza estån basadas frecuentemente en nociones físicas, químicas y geológicas, ${ }^{48}$ Lugones tiene siempre presente su concepción de la unidad de la materia. Por eso las imágenes se van organizando alrededor de sus conocimientos minerales, astronómicos y físicos, cuando la realidad contemplada incluye cambios de colores y cambios atmosféricos. Recuérdese también que en La guerra gaucba las fuerzas de la naturaleza se inclinan en favor de los patriotas en la lucha contra los realistas. ${ }^{49}$ De acuerdo a sus ideas sobre las relaciones entre pensamiento y energía, Lugones introduce una nueva justificación a las intervenciones de los elementos - -rayos, temblores, tempestades-en las acciones humanas, y el valor épico-mítico de la obra se acrecienta cuando se la considera a la luz de su cosmogonía.

Finalmente, su manera de interpretar la historia y el destino de los pueblos, tal como aparece en El Imperio Jesuitico (iI904), responde a esta misma filosofía. El profundo pesimismo que respira esta obra con respecto a la capacidad del hombre para organizarse políticamente está relacionado con la idea de la evolución perpetua, pero sin la noción de progreso, de acuerdo al postulado de que la historia se reduce a una por-

48 Allen W. Phillips ("La prosa artística de Leopoldo Lugones en La guerra gaucba", La Torre, Año V, Núm. 17, enero-marzo de 1957, pp. 161-198) ha estudiado la frecuencia con que Lugones acude a la ciencia en sus descripciones de la naturaleza (pp. 178-179).

49 Phillips, pp. 182-183. 
ción de eternidad, en cuyo ámbito se desarrolla una continua desintegración del universo, que volverá a integrarse en otro planeta, después de un nuevo diluvio. Este hecho, aparentemente irrelevante, entraña la raíz de la angustia metafísica que Lugones trata inútilmente de disimular. La historia de la humanidad, por ejemplo, no es un proceso ascendente, ya que tanto el espíritu como la materia, que en última instancia son una sola y misma cosa, alcanzaron ya, al menos en este planeta, su momento culminante al llegar a la forma sólida, que conlleva la aparición de los animales superiores, el hombre en primer término. Desde entonces empieza el retroceso, el fenómeno inverso. La radioactividad, que produjo la aglutinación de la materia en sus tres estados, empieza a escapar (de paso, poco antes se había descubierto el radio y con él el proceso natural de la desintegración atómica) para volver al estado primitivo de pura energía, desprovista de materia, que según la concepción del autor, no es otra cosa que la confluencia de tiempo y espacio.

Una observación final a propósito de la ficción científica de Lugones: la tarea que se impuso-iquién se atrevería a negar que en gran medida la cumplió? - fue enfocar el lente de la intuición en las leyes científicas, efectuar, por vías imaginativas, su extensión, en un proceso que mucho tiene del que emplea el poeta en su visión metafórica, podría decirse impresionismo científico, frase que Lugones seguramente no habría aprobado, pero que a mi juicio resume con exactitud la esencia de la obra. 
